CrossMark <click for updates

Cite this: Phys. Chem. Chem. Phys., 2016, 18, 15399

Received 24th March 2016, Accepted 6th May 2016

DOI: $10.1039 / c 6 c p 01956 k$

www.rsc.org/pccp

\section{Vacuum ultraviolet photodissociation of hydrogen bromide}

\author{
Shu Su, ${ }^{\text {ab }}$ Yvonne Dorenkamp, ${ }^{c}$ Shengrui Yu, ${ }^{a}$ Alec M. Wodtke, ${ }^{c}$ Dongxu Dai, ${ }^{a}$ \\ Kaijun Yuan*a and Xueming Yang ${ }^{* a}$
}

\begin{abstract}
Photodissociation dynamics of $\mathrm{HBr}$ at a series of photolysis wavelengths in the range of 123.90$125.90 \mathrm{~nm}$ and at around $137.0 \mathrm{~nm}$ have been studied using the $\mathrm{H}$ atom Rydberg "tagging" time-offlight technique. The branching fractions between the channels forming ground $\operatorname{Br}\left({ }^{2} \mathrm{P}_{3 / 2}\right)$ and spin-orbit excited $\mathrm{Br}\left({ }^{2} \mathrm{P}_{1 / 2}\right)$ atoms together with the angular distributions of the products corresponding to these two channels have been measured. The photolysis wavelengths in this work excited the $\mathrm{HBr}$ molecule from the ground state $X^{1} \Sigma^{+}$to various Rydberg states and the $V^{1} \Sigma^{+}$ion-pair valence state. Predissociation via these states displays rich behavior, indicating the influence of the nature of initially excited states and the coupling to other bound or repulsive states on the predissociation dynamics.
\end{abstract}

\section{Introduction}

Photodissociation of hydrogen halides is important in the study of the atmospheric chemistry of the Earth and other solar and stellar objects. ${ }^{1-3}$ Hydrogen halides are known to contribute to atmospheric pollution and are involved in the mechanism of ozone depletion. ${ }^{4-8}$ They are also employed as model systems for studying molecular photodissociation dynamics on multiple potential energy curves (PECs). ${ }^{9-20}$ As one of these prototypical systems, the photodissociation of hydrogen bromide $(\mathrm{HBr})$ has been the subject of extensive experimental and theoretical studies, especially in the near ultraviolet (UV) region corresponding to the first UV absorption band, ${ }^{21-30}$ which is broad, featureless and typical of prompt dissociation. ${ }^{31}$ The PECs involved in the UV photofragmentation of $\mathrm{HBr}$ correlate adiabatically to the formation of ground state $\left({ }^{2} \mathrm{~S}\right)$ hydrogen atoms and bromine atoms in either of the two ground state $\left({ }^{2} \mathrm{P}\right)$ spinorbit components:

$$
\begin{gathered}
\mathrm{HBr}+h \nu \rightarrow \mathrm{H}\left({ }^{2} \mathrm{~S}\right)+\operatorname{Br}\left({ }^{2} \mathrm{P}_{3 / 2}\right) \\
\rightarrow \mathrm{H}\left({ }^{2} \mathrm{~S}\right)+\operatorname{Br}\left({ }^{2} \mathrm{P}_{1 / 2}\right) .
\end{gathered}
$$

Hereafter the ground state bromine atom $\operatorname{Br}\left({ }^{2} \mathrm{P}_{3 / 2}\right)$ is referred to as $\mathrm{Br}$, and the excited state atom $\operatorname{Br}\left({ }^{2} \mathrm{P}_{1 / 2}\right)$ as $\mathrm{Br}^{*}$ in keeping with tradition. The branching fraction $\Gamma$ between channels (1a) and (1b) is defined as:

\footnotetext{
${ }^{a}$ State key Laboratory of Molecular Reaction Dynamics, Dalian Institute of Chemical Physics, Chinese Academy of Sciences, 457 Zhongshan Road, Dalian 116023, China.E-mail: xmyang@dicp.ac.cn,kjyuan@dicp.ac.cn

${ }^{b}$ University of the Chinese Academy of Sciences, Beijing 100049, China

${ }^{c}$ Institut fur PhysikalischeChemie, Georg-August-Universitat and Max-Planck-Institut fur biophysikalischeChemie, Gottingen, Germany
}

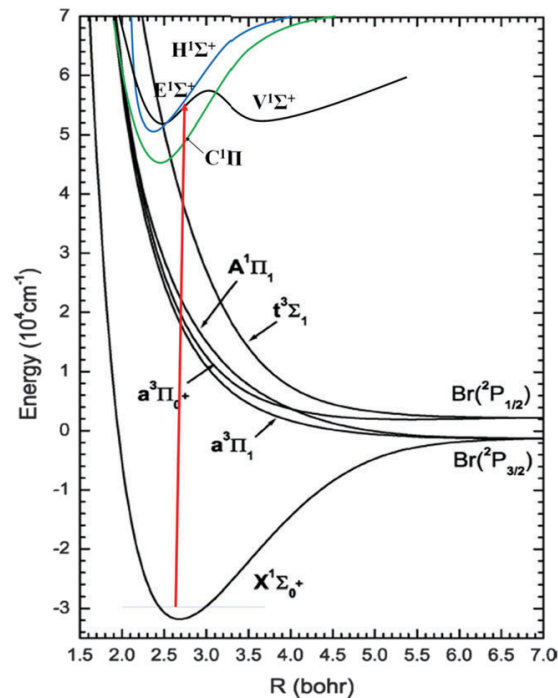

Fig. 1 The schematics of potential energy curves for $\mathrm{HBr}$ adapted from ref. 29 and 32 with some modifications.

$$
\Gamma=\frac{\sigma\left[\mathrm{Br}^{*}\right]}{\sigma[\mathrm{Br}]+\sigma\left[\mathrm{Br}^{*}\right]}
$$

where $\sigma[\mathrm{Br}]$ and $\sigma\left[\mathrm{Br}^{*}\right]$ are the cross-sections at a particular wavelength for the formation of $\mathrm{Br}$ and $\mathrm{Br}^{*}$, respectively.

Among the potential energy curves correlating with the $\mathrm{H}\left({ }^{2} \mathrm{~S}\right)+\operatorname{Br}\left({ }^{2} \mathrm{P}\right)$ asymptote, the $\mathrm{X}{ }^{1} \Sigma^{+}, \mathrm{A}{ }^{1} \Pi, \mathrm{a}^{3} \Pi_{2}, \mathrm{a}{ }^{3} \Pi_{1}$ and a ${ }^{3} \Pi_{0}{ }^{-}$states correlate adiabatically with $\left.\mathrm{H}^{2} \mathrm{~S}\right)+\operatorname{Br}\left({ }^{2} \mathrm{P}_{3 / 2}\right)$, while the $\mathrm{t}^{3} \Sigma^{+}$and a ${ }^{3} \Pi_{0}^{+}$states correlate with $\mathrm{H}\left({ }^{2} \mathrm{~S}\right)+\operatorname{Br}\left({ }^{2} \mathrm{P}_{1 / 2}\right)$, and only the $\mathrm{X}^{1} \Sigma^{+}$state is bound, ${ }^{26}$ as shown in Fig. 1 . In the limit of infinitely slow recoil of photofragments, these correlations 
are rigorous. However, for separation at a finite velocity, the continuum states become coupled, and in the diabatic (statistical) limit, all the continuum states except for a ${ }^{3} \Pi_{2}$ correlate with both spin-orbit states of $\operatorname{Br}\left({ }^{2} \mathrm{P}\right) .{ }^{10}$

Although there has been considerable experimental and theoretical interest in the photodissociation of $\mathrm{HBr}$ following excitation to the repulsive valence states in the near UV region, to our knowledge, the investigation of the predissociation mechanism of Rydberg states and the $\mathrm{V}^{1} \Sigma^{+}$ion-pair valence state with excitation energy lying in the vacuum ultraviolet (VUV) region is still lacking. The VUV and multiphoton spectra of $\mathrm{HBr}$ due to excitation to Rydberg and ion-pair states are found to be rich in intensity anomalies caused by state interactions and predissociation processes. ${ }^{32-39}$ Compared with the dissociation of $\mathrm{HBr}$ from the repulsive states, the predissociation processes will involve a number of complications, for example, the coupling of the excited state to different repulsive states or to some gateway state which is itself coupled to the repulsive states. The latter will be important if there is no direct coupling between the excited state and the repulsive states.

In this work, we applied the technique of $\mathrm{H}$ atom Rydberg "tagging" time-of-flight to a study of the photolysis of $\mathrm{HBr}$ molecules via different rovibrational levels of various Rydberg states and the $\mathrm{V}^{1} \Sigma^{+}$valence state. The branching fractions and the angular distributions for the photofragments formed in channels (1a) and (1b) were measured in order to get some clues about the non-adiabatic coupling of various potential energy curves during the dissociation process.

\section{Experimental methods}

The photodissociation dynamics of $\mathrm{HBr}$ at a series of photolysis wavelengths in the range of $123.90-125.90 \mathrm{~nm}$ and at around $137.0 \mathrm{~nm}$ were investigated using the $\mathrm{H}$ atom Rydberg "tagging" time-of-flight (TOF) technique, which has been described in detail elsewhere, ${ }^{40,41}$ and only a brief description is presented here. In this experiment, the $\mathrm{HBr}$ molecular beam was formed by expanding a neat $\mathrm{HBr}$ sample with a backing pressure of $\sim 760$ Torr via a pulsed general valve. After the HBr expansion passed through a skimmer, it was intercepted by the output of the photolysis laser. The nascent $\mathrm{H}$ atom products in the photolysis region were excited from the ground state to a high Rydberg state via a two-step excitation. In the first excitation step, the $\mathrm{H}$ atoms were excited to the $n=2$ state by a $121.6 \mathrm{~nm}$ VUV laser generated by the difference four wave mixing (DFWM) method of 212.5 and $845 \mathrm{~nm}$ laser in a $\mathrm{Kr}$ gas cell, in which two photons of $212.5 \mathrm{~nm}$ are in resonance with the $\mathrm{Kr} 4 \mathrm{p}-5 \mathrm{p}[1 / 2,0]$ transition. ${ }^{42}$ In the second step, the $\mathrm{H}(n=2)$ atoms were sequentially excited to a high Rydberg state with $n \approx 50$ using a $365 \mathrm{~nm}$ laser. The neutral Rydberg $\mathrm{H}$ atoms, following a fieldfree path of about $74 \mathrm{~cm}$, were field ionized in front of a microchannel plate (MCP) detector. The signal received by the MCP was amplified by a fast preamplifier, and counted by a multichannel scaler. The tunable VUV photolysis source was also generated by the DFWM method with the same $212.5 \mathrm{~nm}$ laser for generating $121.6 \mathrm{~nm}$ and another tunable laser $\lambda_{\mathrm{T}}(470-480$ and $680-750 \mathrm{~nm}) .{ }^{41}$ The polarization of the photolysis source can be changed by rotating the polarization of the $\lambda_{\mathrm{T}}$ laser using a set of half waveplates for angular anisotropy measurements. The detection axis, the molecular beam, and the photolysis laser beam are mutually perpendicular.

\section{Results and discussion}

The action spectra of jet-cooled $\mathrm{HBr}$ molecules were recorded for the VUV laser beam region 123.9-125.9 nm (79428-80 $\left.710 \mathrm{~cm}^{-1}\right)$ and at around $137.0 \mathrm{~nm}\left(72993 \mathrm{~cm}^{-1}\right)$, as shown in Fig. 2(a-d). Peaks due to one-photon excitation from the ground state $\mathrm{X}^{1} \Sigma^{+}$ to various Rydberg states $\left(\mathrm{C}^{1} \Pi, \mathrm{E}^{1} \Sigma^{+}, \mathrm{H}^{1} \Sigma^{+}\right.$, etc. $)$and the $\mathrm{V}^{1} \Sigma^{+}$ ion-pair valence state are assigned, according to the spectroscopic data reported by Ginter et al. ${ }^{37,39}$ The clearly resolved rotational structures allow us to study the photodissociation dynamics of $\mathrm{HBr}$ molecules at the state-to-state level.

TOF spectra of the $\mathrm{H}$ atom products from the photodissociation of $\mathrm{HBr}$ have been measured using the above experimental methods. The detecting light beams (121.6 and $212.5 \mathrm{~nm}$ ) could also generate $\mathrm{H}$ atom products from $\mathrm{HBr}$. However, because of the differences in photolysis energies, the signal from dissociation at the photolysis wavelengths in this work can be clearly separated in the TOF spectra from those of the detecting lasers. At each photolysis wavelength, the TOF spectra with the photolysis laser polarization parallel and perpendicular to the detection axis were measured. As an example, the $\mathrm{H}$ atom TOF spectra in both polarizations at $137.062 \mathrm{~nm}$ and $125.489 \mathrm{~nm}$ are shown in Fig. 3(a) and (b). Each of the TOF spectra at different photolysis wavelengths shows two peaks corresponding to the two spin-orbit split channels: $\mathrm{H}+\operatorname{Br}\left({ }^{2} \mathrm{P}_{3 / 2}\right)$ (fast) and $\mathrm{H}+\operatorname{Br}\left({ }^{2} \mathrm{P}_{1 / 2}\right)$ (slow). The TOF spectra have been converted to the total translational energy distributions of the $\mathrm{H}$ and $\mathrm{Br}$ products,

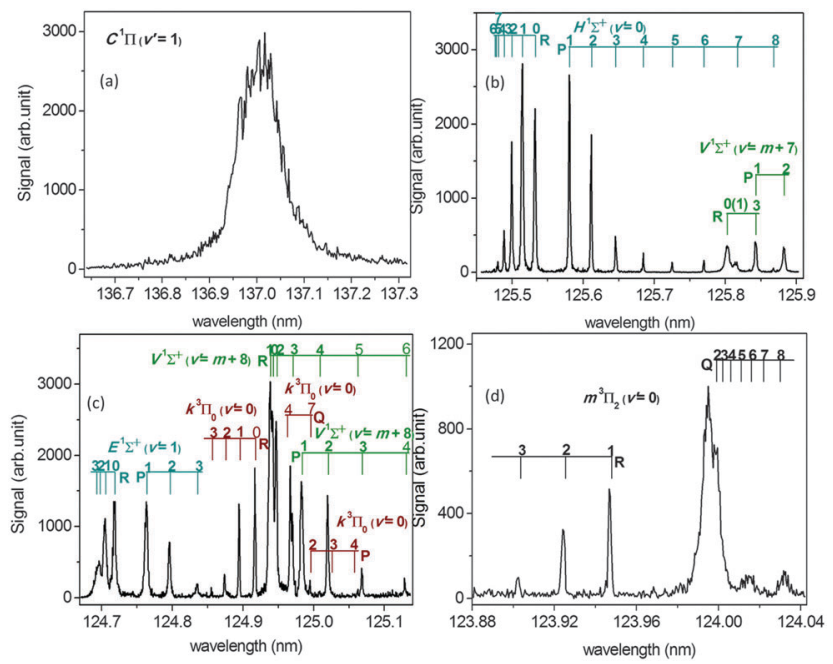

Fig. 2 The photodissociation action spectrum of $\mathrm{HBr}$ at around $137.0 \mathrm{~nm}$ (a), at 125.4-125.9 nm (b), 124.7-125.1 nm (c), and 123.9-124.1 nm (d). The assignments are adapted from ref. 37 and 39 . 

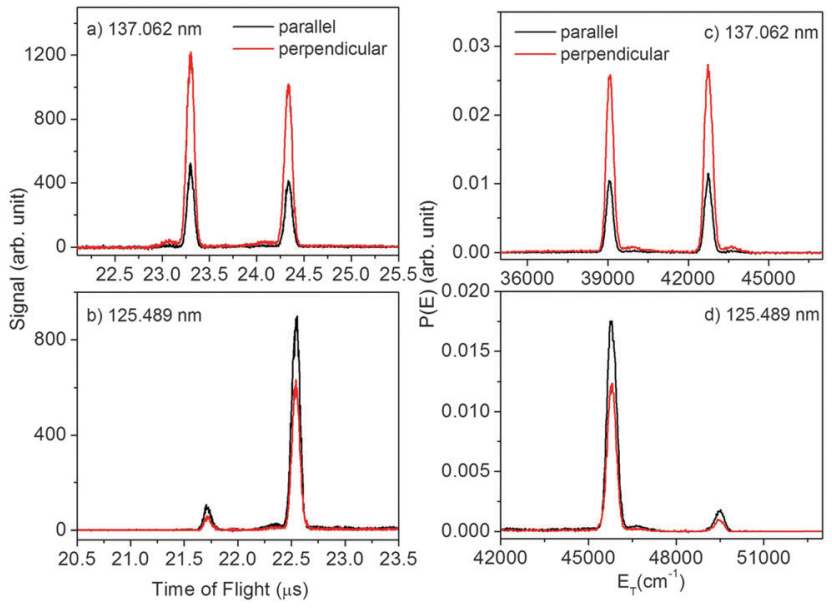

Fig. 3 Time-of-flight spectra of the $\mathrm{H}$ atom product from the photodissociation of $\mathrm{HBr}$ at $137.062 \mathrm{~nm}$ (a) and $125.489 \mathrm{~nm}$ (b) with photolysis laser polarization parallel and perpendicular to the detection axis and the corresponding total product translational energy distributions at $137.062 \mathrm{~nm}$ (c) and $125.489 \mathrm{~nm}(\mathrm{~d})$.

as shown in Fig. 3(c) and (d) (take $137.062 \mathrm{~nm}$ and $125.489 \mathrm{~nm}$ as examples), using a computer program that includes allowance for the velocity of the molecular beam.

Because the total energy is conserved in the dissociation process and the $\mathrm{H}$-atom product has no internal energy deposit, for a parent molecule with $v=0$ and $J=0$ :

$$
\text { TKER }=h \nu-E(\mathrm{Br})_{\text {int }}-D_{0}(\mathrm{H}-\mathrm{Br}) .
$$

The bond energy, $D_{0}(\mathrm{H}-\mathrm{Br})$, is determined to be $30175 \pm 30 \mathrm{~cm}^{-1}$ in this work, which compares favorably with the value reported by Ashfold ${ }^{27}$ and Okabe. ${ }^{43}$

In a one-photon molecular photodissociation process, the photodissociation products detected at an angle in the centerof-mass frame $\left(\theta_{\mathrm{cm}}\right)$ relative to the photolysis photon polarization can be represented by the following formula:

$$
\psi\left(E_{\mathrm{T}}, \theta_{\mathrm{cm}}\right)=\sigma\left(E_{\mathrm{T}}\right)\left\{1+\beta\left(E_{\mathrm{T}}\right) P_{2}\left(\cos \theta_{\mathrm{cm}}\right)\right\}
$$

where $\sigma\left(E_{\mathrm{T}}\right)$ is the product translational energy distribution, $\beta\left(E_{\mathrm{T}}\right)$ is the translational energy dependent anisotropy parameter, and $P_{2}\left(\cos \theta_{\mathrm{cm}}\right)=\left(3 \cos ^{2} \theta_{\mathrm{cm}}-1\right) / 2$ is the second order Legendre polynomial. The value of the $\beta$ is between -1 and 2 . $\beta=-1$ corresponds to a pure perpendicular transition while $\beta=2$ corresponds to a pure parallel transition. In this experiment, the translational energy distributions at two photolysis laser polarizations (parallel and perpendicular to the detection axis) were measured, therefore the anisotropy parameters $\beta$ for both $\mathrm{H}+\mathrm{Br}$ and $\mathrm{H}+\mathrm{Br}^{*}$ channels from the dissociation of $\mathrm{HBr}$ at different photolysis wavelengths and the branching ratios of the 2 channels can be determined.

The first-order bound-continuum and bound-bound interactions for different states are reported by Alexander et al., ${ }^{11}$ which can help us to understand the predissociation dynamics. The bound-bound interactions are important for the states having weak or no first-order coupling to the continuum states.

\section{A. Photodissociation dynamics at around $137 \mathbf{n m}$}

The three photolysis wavelengths at around $137 \mathrm{~nm}$ in this work correspond to the $\mathrm{C}^{1} \Pi\left(v^{\prime}=1\right) \leftarrow \mathrm{X}^{1} \Sigma^{+}\left(v^{\prime \prime}=0\right)$ transition of $\mathrm{HBr}$. The $\mathrm{C}$ state is the lowest-lying singlet Rydberg state of $\mathrm{HBr}$ and is strongly predissociated. ${ }^{37}$ It is configurationally mixed with the repulsive A state, and is also perturbed by two other continuum states. Due to the strong predissociation of the $\mathrm{C}$ state, it can serve as a gateway for other high-lying electronic states. As shown in Fig. 2(a), we can determine the $\mathrm{C}\left(v^{\prime}=1\right)$ state bandwidth in the action spectrum to be about $53 \mathrm{~cm}^{-1}$. This gives an estimated lifetime of about 100 fs for the $\mathrm{C}\left(v^{\prime}=1\right)$ state. The short lifetime is consistent with strong coupling between the $\mathrm{C}$ state and the repulsive states. The branching fractions $\Gamma$ and the anisotropy parameters $\beta$ for the 2 channels, $\mathrm{H}+\mathrm{Br}$ and $\mathrm{H}+\mathrm{Br}^{*}$, are listed in Table 1. The branching fraction is near 0.5 for all the three wavelengths and may give an indication of the branching ratio of the different coupling mechanisms. As reported by Alexander et al., ${ }^{11}$ the predissociation of the $\mathrm{C}$ state can proceed through three coupling mechanisms: configurational mixing with the $\mathrm{A}^{1} \Pi$ state and spin-orbit coupling with the a ${ }^{3} \Pi_{1}$ and ${ }^{3} \Sigma_{1}{ }^{+}$states. The potential energy curves of $\mathrm{HBr}$ are shown in Fig. 1. It is to be noted that the $\mathrm{A}^{1} \Pi$ and $\mathrm{a}^{3} \Pi_{1}$ states correlate adiabatically with $\mathrm{H}\left({ }^{2} \mathrm{~S}\right)+\operatorname{Br}\left({ }^{2} \mathrm{P}_{3 / 2}\right)$, while the $\mathrm{t}^{3} \Sigma^{+}$and a ${ }^{3} \Pi_{0}{ }^{+}$states correlate with $\mathrm{H}\left({ }^{2} \mathrm{~S}\right)+\operatorname{Br}\left({ }^{2} \mathrm{P}_{1 / 2}\right)$. The observed branching fractions $\Gamma$ mean that the coupling strength between the $\mathrm{C}$ state and the $\mathrm{t}^{3} \Sigma_{1}{ }^{+}$ state is comparable with that between the $\mathrm{C}$ state and the other two states. It is also believed that the coupling strength between the $\mathrm{C}$ state and the $\mathrm{t}^{3} \Sigma_{1}{ }^{+}$state is a little stronger at higher excitation energy, since the branching fraction of $\mathrm{Br}^{*}$ increases with the excitation energy. The negative values of $\beta$ are consistent with the perpendicular (i.e., $\Delta \Omega=1$ ) characteristics of the $\mathrm{C} \leftarrow \mathrm{X}$ transition. In addition, the values of $\beta$ being obviously larger than -1 is related to the fact that the $C$ state is bound, different from the prompt dissociation from a repulsive state. The observed lifetime of the $\mathrm{C}$ state is also longer than that of a typical repulsive state. The nearly identical $\beta$ values for the 2 channels at a certain wavelength indicate that the different couplings and subsequent processes have much less influence than the initially excited state on the angular distribution of the products.

\section{B. Photodissociation dynamics at $125.883-125.475 \mathrm{~nm}$}

The photolysis wavelengths used in the present work in the range of 125.883-125.475 $\mathrm{nm}$ excite the $\mathrm{HBr}$ molecule from the $\mathrm{X}^{1} \Sigma^{+}\left(v^{\prime \prime}=0\right)$ state to the Rydberg state, $\mathrm{H}^{1} \Sigma^{+}\left(v^{\prime}=0\right)$, or the

Table 1 Branching fractions $\Gamma$ and anisotropy parameters $\beta$ for the photodissociation of $\mathrm{HBr}$ via the $\mathrm{C}^{1} \Pi\left(v^{\prime}=1\right)$ state

\begin{tabular}{llll}
\hline & & \multicolumn{3}{l}{$\beta$} \\
\cline { 3 - 4 } Wavelength $(\mathrm{nm})$ & $\Gamma$ & $\mathrm{H}+\mathrm{Br}$ & $\mathrm{H}+\mathrm{Br}^{*}$ \\
\hline 136.951 & 0.504 & -0.263 & -0.276 \\
137.012 & 0.499 & -0.246 & -0.229 \\
137.062 & 0.485 & -0.478 & -0.497
\end{tabular}




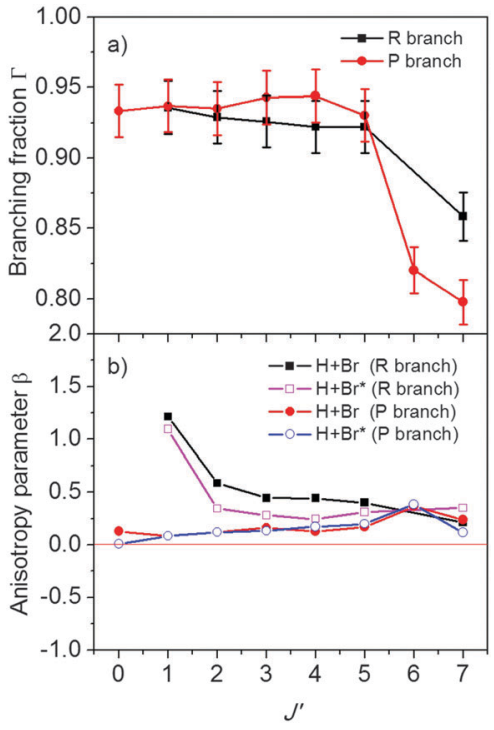

Fig. 4 Branching fractions $\Gamma$ and anisotropy parameters $\beta$ as a function of $J^{\prime}$ for the photodissociation of $\mathrm{HBr}$ via the $\mathrm{H}\left(v^{\prime}=0\right)$ state.

ion-pair state, $\mathrm{V}^{1} \Sigma^{+}\left(v^{\prime}=m+7\right)$. Vibrational assignments $\left(v^{\prime}\right)$ for the $\mathrm{V}$ state are uncertain and marked as $v^{\prime}=m+i$, where $i$ is an integer starting from $i=0$ for the lowest energy level observed and $m$ is an unknown integer. ${ }^{39}$

For the photodissociation via the $\mathrm{H}\left(v^{\prime}=0\right)$ state, each wavelength in this work corresponds to a single rotational line of the $\mathrm{H}\left(v^{\prime}=0, J^{\prime}\right) \leftarrow \mathrm{X}\left(v^{\prime \prime}=0, J^{\prime \prime}\right)$ transition. As shown in Fig. 2(b), the bandwidths of these rotational lines in the action spectrum are between 1.2 and $2.0 \mathrm{~cm}^{-1}$. This gives an estimated lifetime of about 2.5-4.0 ps for the rotational levels of the $\mathrm{H}\left(v^{\prime}=0\right)$ Rydberg state. The much longer lifetime of the $\mathrm{H}$ state than that of the $\mathrm{C}$ state may be due to the much lower rates of crossing from the Rydberg state to continua. Fig. 4 shows the branching fractions $\Gamma$ and the anisotropy parameters $\beta$ as a function of $J^{\prime}$. As shown in Fig. 4(a), population inversions of the two spin-orbit components of the $\operatorname{Br}\left({ }^{2} \mathrm{P}\right)$ product were observed. The values of $\Gamma$ are in the range of 0.92-0.95 for $J^{\prime}=0-5$, which means that the product $\mathrm{Br}^{*}$ is dominant. This is because the predissociation of the $\mathrm{H}$ state can proceed through spin-orbit coupling with the a ${ }^{3} \Pi_{0}^{+}$state, which correlates with $\mathrm{H}\left({ }^{2} \mathrm{~S}\right)+\operatorname{Br}\left({ }^{2} \mathrm{P}_{1 / 2}\right)$, as reported by Alexander et al. ${ }^{11}$ The values of $\Gamma$ drop below 0.86 when $J^{\prime} \geq 6$, implying that there may be a change in the surface coupling at $J^{\prime}=6$. Positive $\beta$ values for each wavelength are consistent with the initial parallel (i.e., $\Delta \Omega=0$ ) transition (Fig. 4(b)). Due to the long predissociation lifetime, the values of $\beta$ are far away from the parallel limited value of 2 , except for $J^{\prime}=1$ in the $\mathrm{R}$ branch (the reason is not known immediately. It may be caused by the influence of the rotational states of the ground state and the excited state). It is to be noted that for the dissociation channels $\mathrm{H}+\mathrm{Br}$ and $\mathrm{H}+\mathrm{Br}^{*}$ at the same $J^{\prime}$, similar values of $\beta$ appeared in the $\mathrm{P}$ branch and the $\mathrm{R}$ branch, which means coupling to different repulsive states has a limited effect on the orientational dynamics of dissociation processes.

In the case of photodissociation via the $\mathrm{V}^{1} \Sigma^{+}\left(v^{\prime}=m+7\right)$ state, the photolysis wavelength of $125.883 \mathrm{~nm}$ corresponds to
Table 2 Branching fractions $\Gamma$ and anisotropy parameters $\beta$ for the photodissociation of $\mathrm{HBr}$ via the $\mathrm{V}^{1} \Sigma^{+}\left(v^{\prime}=m+7\right)$ state

\begin{tabular}{lllrr}
\hline & & & \multicolumn{3}{c}{$\beta$} \\
\cline { 3 - 5 } Wavelength $(\mathrm{nm})$ & Assignment & $\Gamma$ & $\mathrm{H}+\mathrm{Br}$ & $\mathrm{H}+\mathrm{Br}^{*}$ \\
\hline 125.803 & $\mathrm{R}(0)$ or $\mathrm{R}(1)$ & 0.876 & 0.217 & 0.858 \\
125.843 & $\mathrm{R}(3)$ or $\mathrm{P}(1)$ & 0.936 & -0.027 & -0.021 \\
125.883 & $\mathrm{P}(2)$ & 0.910 & -0.022 & 0.081
\end{tabular}

the $\mathrm{P}(2)$ line of $\mathrm{V}\left(v^{\prime}=m+7\right) \leftarrow \mathrm{X}\left(v^{\prime \prime}=0\right)$ transition, while $125.843 \mathrm{~nm}$ to the $\mathrm{P}(1)$ or $\mathrm{R}(3)$ lines and $125.803 \mathrm{~nm}$ to the $\mathrm{R}(0)$ or R(1) lines because of the blend of lines. ${ }^{39}$ These assignments are listed in Table 2 together with the corresponding $\Gamma$ and $\beta$ values. The potential energy curve of the $\mathrm{V}$ state is broader and has a larger $R_{\min }$ (internuclear separation at the potential minimum) than the potential energy curves of the Rydberg states associated with the $\left(\sigma^{2} \pi^{3}\right) \mathrm{X}^{3} \Pi_{\mathrm{i}}$ ground core of the molecular ion (e.g., all the Rydberg states involved in this work). This makes the crossing from the V state to repulsive states highly improbable, because of the reason that the repulsive walls are at much shorter internuclear distances. ${ }^{32,39}$ Hence, the predissociation of the V state may occur via crossings to Rydberg states such as the $\mathrm{H}$ and $\mathrm{E}$ states. Similar to the photodissociation via the $\mathrm{H}\left(v^{\prime}=0\right)$ state, the $\mathrm{Br}^{*}$ products are also dominant. For 125.883 and $125.843 \mathrm{~nm}$, nearly isotropic angular distributions $(\beta \sim 0)$ of the products were observed. Meanwhile, for $125.803 \mathrm{~nm}, \beta$ for the $\mathrm{H}+\mathrm{Br}$ channel is smaller than that at the corresponding rotational lines (i.e., $\mathrm{R}(0)$ and $\mathrm{R}(1))$ of $\mathrm{H}\left(v^{\prime}=0\right) \leftarrow \mathrm{X}\left(v^{\prime \prime}=0\right)$ transition, and for the $\mathrm{H}+\mathrm{Br}^{*}$ channel, $\beta$ is smaller than that at the $\mathrm{R}(0)$ line. The more isotropic distributions imply that after the initial excitation, it may take a longer time for coupling of the $\mathrm{V}$ state to the Rydberg states and then from the Rydberg state to the repulsive states.

\section{Photodissociation dynamics at 125.131-124.697 nm}

Photodissociation of $\mathrm{HBr}$ via the $\mathrm{k}{ }^{3} \Pi_{0} \quad\left(v^{\prime}=0\right)$ and $\mathrm{V}^{1} \Sigma^{+}\left(v^{\prime}=m+8\right)$ states is responsible for the photolysis wavelengths in the range of 125.131-124.854 $\mathrm{nm}$ and the $\mathrm{E}^{1} \Sigma^{+}\left(v^{\prime}=1\right)$ state for $124.836-124.697 \mathrm{~nm} .{ }^{39}$

Each wavelength in this work corresponding to the $\mathrm{k}^{3} \Pi_{0}$ $\left(v^{\prime}=0\right) \leftarrow \mathrm{X}^{1} \Sigma^{+}\left(v^{\prime \prime}=0\right)$ transition can be attributed to a single rotational line, except for $124.997 \mathrm{~nm}$, which can be attributed to the $\mathrm{P}(2)$ or $\mathrm{Q}(7)$ lines due to the blend of lines. ${ }^{39}$ For the $\mathrm{R}$ branch without blended lines, the differences in $\Gamma$ between $J^{\prime}=1$ and $J^{\prime}=2-4$ are much larger than the differences between any two $\Gamma$ values at $J^{\prime}=2-4$ (Fig. 5(a)), and similar phenomena can be observed in the $J^{\prime}$-dependence of $\beta$ (Fig. 5(b)). In addition, while similar $\beta$ values for the 2 channels are seen for $J^{\prime}=2-4$, isotropic and anisotropic distributions of the products were observed at $J^{\prime}=1$ for $\mathrm{H}+\mathrm{Br}$ and $\mathrm{H}+\mathrm{Br}^{*}$ respectively, implying that the coupling to lower Rydberg states may play a more important role in the predissociation process forming $\mathrm{H}+\mathrm{Br}$ than $\mathrm{H}+\mathrm{Br}^{*}$ at $J^{\prime}=1$. Accordingly, there may be different predissociation mechanisms involved in the two regions of $J^{\prime}$.

Another interesting observation is the slight but notable difference in $\Gamma$ at $J^{\prime}=4$ between the $\mathrm{R}$ branch and the $\mathrm{Q}$ branch (Fig. 5(a)). The possible reason is that the potential energy curve 


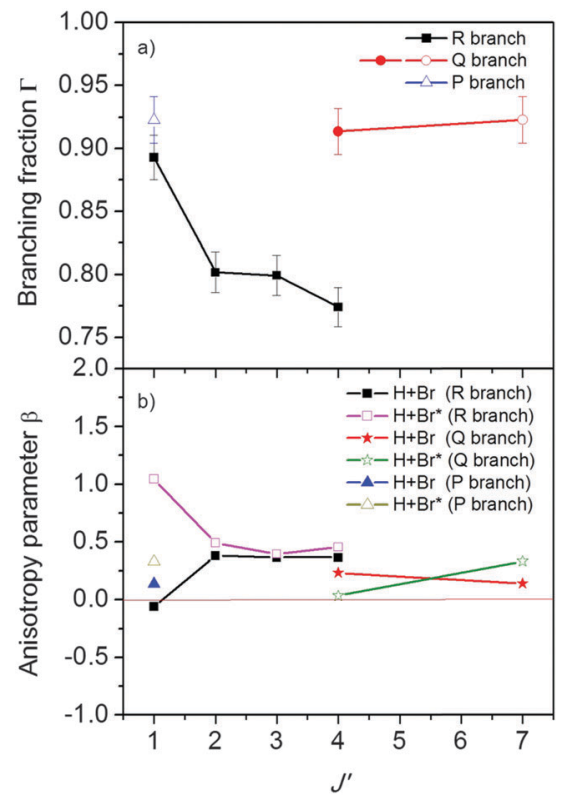

Fig. 5 Branching fractions $\Gamma$ and anisotropy parameters $\beta$ as a function of $J^{\prime}$ for the photodissociation of $\mathrm{HBr}$ via the $\mathrm{k}^{3} \Pi_{0}\left(v^{\prime}=0\right)$ state (the results obtained at $124.997 \mathrm{~nm}$ can be assigned to $\mathrm{P}(2)$ or $\mathrm{Q}(7)$ lines due to the blend of lines).

of the Rydberg state $\mathrm{k}^{3} \Pi_{0}\left(v^{\prime}=0\right)$ around the Franck-Condon region is close to that of the repulsive state $\mathrm{t}^{3} \Sigma_{1}{ }^{+}$at shorter wavelengths, analogous to the case of $\mathrm{HI}^{20}$ This means that the wavelengths of $\mathrm{R}(3)$ and $\mathrm{Q}(4)$ lines may overlap the $\mathrm{t}^{3} \Sigma_{1}^{+} \leftarrow \mathrm{X}^{1} \Sigma^{+}$band, so that not only the excitation to the $\mathrm{k}^{3} \Pi_{0}$ $\left(v^{\prime}=0\right)$ state and the corresponding rovibronic transitions from the $\mathrm{k}^{3} \Pi_{0}\left(v^{\prime}=0\right)$ to the $\mathrm{t}^{3} \Sigma_{1}{ }^{+}$state but also the direct excitation to the $\mathrm{t}^{3} \Sigma_{1}{ }^{+}$state will happen. The branching ratios between the two kinds of initial transitions may be different at the two wavelengths, consequently resulting in different values of $\Gamma$. It is to be noted that the photodissociation initiated by the $\mathrm{t}^{3} \Sigma_{1}{ }^{+} \leftarrow \mathrm{X}^{1} \Sigma^{+}$transition should result in $\mathrm{H}+\mathrm{Br}^{*}$ products predominantly and nearly purely perpendicular distributions of the products in both channels. Therefore, slight positive $\beta$ values in Fig. 5(b) suggest that the $\mathrm{t}^{3} \Sigma_{1}{ }^{+} \leftarrow \mathrm{X}^{1} \Sigma^{+}$transition can contribute only a little to the initial excitations and the outcomes should be mainly determined by predissociation of the Rydberg states.

The $J^{\prime}$-dependent branching fractions $\Gamma$ and anisotropy parameters $\beta$ for the photodissociation via the $\mathrm{E}\left(v^{\prime}=1\right)$ state are plotted in Fig. 6 . The values of $\Gamma$ seem to be insensitive to the change in $J^{\prime}$ and lie in the narrow range of 0.92-0.95 (Fig. 6(a)), which may indicate the same predissociation mechanisms for these rotational states. In contrast, the values of $\beta$ decrease with $J^{\prime}$ for the R branch but increase with $J^{\prime}$ for the $\mathrm{P}$ branch (Fig. 6(b)). This may be attributed to the influence from the rotational states of the $\mathrm{X}\left(v^{\prime \prime}=0\right)$ state.

What are also shown in Fig. 6 are the $J^{\prime}$-dependent $\Gamma$ and $\beta$ for the photodissociation via the $\mathrm{V}\left(v^{\prime}=m+8\right)$ state. Similar values to the corresponding rotational lines of the $\mathrm{E}\left(v^{\prime}=1\right)$ state were observed except for the R(2) line. The resemblance

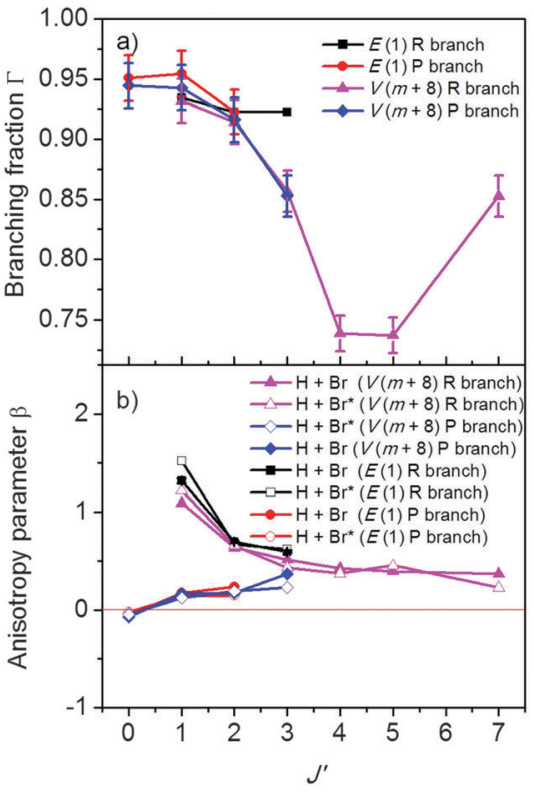

Fig. 6 Branching fractions $\Gamma$ and anisotropy parameters $\beta$ as a function of $J^{\prime}$ for the photodissociation of $\mathrm{HBr}$ via the $\mathrm{E}^{1} \Sigma^{+}\left(v^{\prime}=1\right)$ and $\mathrm{V}^{1} \Sigma^{+}\left(v^{\prime}=m+8\right)$ states (the results obtained at $125.131 \mathrm{~nm}$ can be assigned to $P(4)$ or $R(6)$ lines of $V^{1} \Sigma^{+}\left(v^{\prime}=m+8\right) \leftarrow X^{1} \Sigma^{+}\left(v^{\prime \prime}=0\right)$ transition due to the blend of lines).

can be relative to the interaction between the $\mathrm{V}$ and $\mathrm{E}$ states. The smaller $\Gamma$ at higher $J^{\prime}$ may imply the existence of other interactions, for example, spin-orbit coupling between the $\mathrm{V}^{1} \Sigma^{+}$and $\mathrm{k}^{3} \Pi_{0}$ states.

\section{Photodissociation dynamics at $124.032-123.902 \mathrm{~nm}$}

The photolysis wavelengths studied in this work in the range of 124.032-123.902 nm correspond to several rotational lines of the $\mathrm{m}^{3} \Pi_{2}\left(v^{\prime}=0\right) \leftarrow \mathrm{X}{ }^{1} \Sigma^{+}\left(v^{\prime \prime}=0\right)$ transition of HBr. The branching fractions $\Gamma$ and anisotropy parameters $\beta$ are shown in Fig. 7 as a function of $J^{\prime}$. Although $\Gamma$ increases with $J^{\prime}$ for both $\mathrm{Q}$ and $\mathrm{R}$ branches, there is a little greater propensity to form the spin-orbit excited $\mathrm{Br}^{*}$ product for the photodissociation at the $\mathrm{Q}$ lines than the $\mathrm{R}$ lines (Fig. 7(a)). This can also be explained by the involvement of the $\mathrm{t}^{3} \Sigma_{1}^{+} \leftarrow \mathrm{X}^{1} \Sigma^{+}$transition. Fig. 7(b) shows positive values or around 0 for $\beta$ and nearly the same values for different channels at the same rotational line except for $J^{\prime}=2$, together with the change in $\Gamma$, indicating the change in the predissociation mechanism with $J^{\prime}$.

At present, we cannot rationalize many of the details of the branching fractions between the 2 dissociation channels and the angular distributions of the photofragments. Theoretical calculations are required in order to quantitatively explain the experimental results. Alexander et al. ${ }^{11}$ performed a combined theoretical-experimental investigation of the predissociation of $\mathrm{HCl}\left(\mathrm{C}^{1} \Pi\right)$ and showed that it is much more difficult to model accurately the predissociation of $\mathrm{C}^{1} \Pi$ than the repulsive valence states. A similar situation can be expected in the case of $\mathrm{HBr}$, and modeling the predissociation of higher Rydberg states and the ion-pair $\mathrm{V}^{1} \Sigma^{+}$state will be even more complicated, due to the increase in the number of lower states coupled 


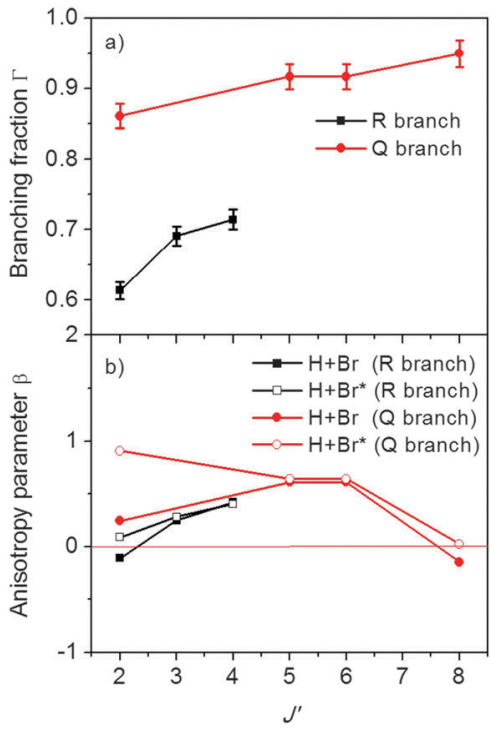

Fig. 7 Branching fractions $\Gamma$ and anisotropy parameters $\beta$ as a function of $J^{\prime}$ for the photodissociation of $\mathrm{HBr}$ via the $\mathrm{m}^{3} \Pi_{2}\left(v^{\prime}=0\right)$ state (the results obtained at $124.014 \mathrm{~nm}$ can be assigned to $Q(5)$ or $Q(6)$ lines).

to the initially excited state, which may be important in the dissociation process.

\section{Conclusion}

$\mathrm{HBr}$ photodissociation dynamics via different rovibrational levels of various Rydberg states and the $\mathrm{V}^{1} \Sigma^{+}$ion-pair valence state have been studied at a series of photolysis wavelengths in the range of 123.90-125.90 $\mathrm{nm}$ and around $137.0 \mathrm{~nm}$ using the $\mathrm{H}$ atom Rydberg "tagging" TOF method. Among the wavelengths studied in the present work, photodissociation of $\mathrm{HBr}$ at longer wavelengths corresponding to the $\mathrm{C}^{1} \Pi\left(v^{\prime}=1\right) \leftarrow \mathrm{X}^{1} \Sigma^{+}\left(v^{\prime \prime}=0\right)$ transition results in branching fractions $\Gamma$ near 0.5 , i.e., the 2 dissociation channels contribute nearly equally to the dissociation, while photodissociation at shorter wavelengths corresponding to the transitions to the other Rydberg states involved in this work and the $\mathrm{V}^{1} \Sigma^{+}$state shows an evident preference for the $\mathrm{H}+\mathrm{Br}^{*}$ channel. The angular distributions of the products reflect the symmetry of the initial absorption step at most of the photolysis wavelengths. However, no purely perpendicular or parallel distribution was observed. This is consistent with the bound characteristics of initially excited states and the involvement of indirect photodissociation pathways. The observations in this work have provided valuable information for understanding the dissociation mechanism of $\mathrm{HBr}$ involving various nonadiabatic processes.

\section{Acknowledgements}

We are very grateful for the support of this work by the National Natural Science Foundation of China (No. 21133006 and 2013CB834604), the Chinese Academy of Sciences and the Ministry of Science and Technology.

\section{References}

1 M. Jura, Astrophys. J., 1974, 190, L33-L34.

2 E. Mahieu, R. Zander, P. Duchatelet, J. W. Hannigan, M. T. Coffey, S. Mikuteit, F. Hase, T. Blumenstock, A. Wiacek, K. Strong, J. R. Taylor, R. L. Mittermeier, H. Fast, C. D. Boone, S. D. McLeod, K. A. Walker, P. F. Bernath and C. P. Rinsland, Geophys. Res. Lett., 2005, 32, L15S08.

3 J. H. Black and A. Dalgarno, Astrophys. J., Suppl. Ser., 1977, 34, 405-423.

4 J. P. D. Abbatt, Geophys. Res. Lett., 1994, 21, 665-668.

5 L. T. Chu and J. W. Heron, Geophys. Res. Lett., 1995, 22, 3211-3214.

6 H. Rieley, H. D. Aslin and S. Haq, J. Chem. Soc., Faraday Trans., 1995, 91, 2349-2351.

7 B. J. Gertner and J. T. Hynes, Science, 1996, 271, 1563-1566.

8 M. P. Chipperfield, D. E. Shallcross and D. J. Lary, J. Chem. Soc., Faraday Trans., 1997, 24, 3025-3028.

9 M. H. Alexander, B. Pouilly and T. Duhoo, J. Chem. Phys., 1993, 99, 1752-1764.

10 R. Liyanage, Y. A. Yang, S. Hashimoto, R. J. Gordon and R. W. Field, J. Chem. Phys., 1995, 103, 6811-6814.

11 M. H. Alexander, X. Li, R. Liyanage and R. J. Gordon, Chem. Phys., 1998, 231, 331-343.

12 D. J. Gendron and J. W. Hepburn, J. Chem. Phys., 1998, 109, 7205-7213.

13 H. M. Lambert, P. J. Dagdigian and M. H. Alexander, J. Chem. Phys., 1998, 108, 4460-4466.

14 S. R. Langford, P. M. Regan, A. J. Orr-Ewing and M. N. R. Ashfold, Chem. Phys., 1998, 231, 245-260.

15 A. Strizhev, X. Li, R. Liyanage, R. J. Gordon and R. W. Field, J. Chem. Phys., 1998, 108, 984-989.

16 P. M. Regan, S. R. Langford, D. Ascenzi, P. A. Cook, A. J. Orr-Ewing and M. N. R. Ashfold, Phys. Chem. Chem. Phys., 1999, 1, 3247-3251.

17 P. M. Regan, D. Ascenzi, C. Clementi, M. N. R. Ashfold and A. J. Orr-Ewing, Chem. Phys. Lett., 1999, 315, 187-193.

18 P. M. Regan, D. Ascenzi, E. Wrede, P. A. Cook, M. N. R. Ashfold and A. J. Orr-Ewing, Phys. Chem. Chem. Phys., 2000, 2, 5364-5374.

19 S. Manzhos, H.-P. Loock, B. L. G. Bakker and D. H. Parker, J. Chem. Phys., 2002, 117, 9347-9352.

20 F. Wang, I. C. Lu, K. Yuan, Y. Cheng, M. Wu, D. H. Parker and X. Yang, Chem. Phys. Lett., 2007, 449, 18-22.

21 F. Magnotta, D. J. Nesbitt and S. R. Leone, Chem. Phys. Lett., 1981, 83, 21-25.

22 Z. Xu, B. Koplitz and C. Wittig, J. Chem. Phys., 1987, 87, 1062-1069.

23 Z. Xu, B. Koplitz and C. Wittig, J. Phys. Chem., 1988, 92, 5518-5523.

24 Y. Matsumi, K. Tonokura, M. Kawasaki and T. Ibuki, J. Chem. Phys., 1990, 93, 7981-7985.

25 T. Kinugawa and T. Arikawa, J. Chem. Phys., 1992, 96, 4801-4804.

26 G. Péoux, M. Monnerville, T. Duhoo and B. Pouilly, J. Chem. Phys., 1997, 107, 70-82. 
27 P. M. Regan, S. R. Langford, A. J. Orr-Ewing and M. N. R. Ashfold, J. Chem. Phys., 1999, 110, 281-288.

28 R. L. Toomes, P. C. Samartzis, T. P. Rakitzis and T. N. Kitsopoulos, Chem. Phys., 2004, 301, 209-212.

29 A. G. Smolin, O. S. Vasyutinskii, G. G. Balint-Kurti and A. Brown, J. Phys. Chem. A, 2006, 110, 5371-5378.

30 D. F. Zhang, J. Math. Chem., 2010, 47, 29-40.

31 B. J. Huebert and R. M. Martin, J. Phys. Chem., 1968, 72, 3046-3048.

32 J. Long, H. R. Hróðmarsson, H. Wang and Á. Kvaran, J. Chem. Phys., 2012, 136, 214315.

33 Á. Kvaran, H. Wang and Á. Logadóttir, J. Chem. Phys., 2000, 112, 10811-10820.

34 Á. Kvaran, Á. Logadóttir and H. Wang, J. Chem. Phys., 1998, 109, 5856-5867.

35 D. Ascenzi, S. R. Langford, M. N. R. Ashfold and A. J. Orr-Ewing, Phys. Chem. Chem. Phys., 2001, 3, 29-43.
36 R. Callaghan and R. J. Gordon, J. Chem. Phys., 1990, 93, 4624-4636.

37 M. L. Ginter and S. G. Tilford, J. Mol. Spectrosc., 1970, 34, 206-221.

38 M. L. Ginter and S. G. Tilford, J. Mol. Spectrosc., 1971, 37, 159-178.

39 D. S. Ginter, M. L. Ginter and S. G. Tilford, J. Mol. Spectrosc., 1981, 90, 152-176.

40 L. Schnieder, K. Seekamp-Rahn, E. Wrede and K. H. Welge, J. Chem. Phys., 1997, 107, 6175-6195.

41 K. Yuan, L. Cheng, Y. Cheng, Q. Guo, D. Dai and X. Yang, Rev. Sci. Instrum., 2008, 79, 124101.

42 J. P. Marangos, N. Shen, H. Ma, M. H. R. Hutchinson and J. P. Connerade, J. Opt. Soc. Am. B, 1990, 7, 1254-1259.

43 H. Okabe, Photochemistry of Small Molecules, Wiley, New York, 1978. 